\title{
AN EXPERIMENTALIST CRITIQUE OF PROGRAMMED INSTRUCTION
}

\author{
BY DAVID C. EPPERSON AND RICHARD A. SCHMUCK
}

RECENTLY A REPRESENTATIVE OF A MAJOR DEVELOPER OF PROGRAMMED INSTRUCTIONAL MATERIALS MADE IT CLEAR TO US THAT THERE ARE LITERALLY NO INTERPERSONAL VARIABLES INVOLVED IN THE PROCESS OF MACHINE LEARNING WORTHY of consideration. He said, "Pupils become so absorbed in their step by step progression that social variables are irrelevant." Such a generalization provoked considerable reflection on our part and revived some basic educational issues concerning the nature of man, knowledge, and learning.

The increasing emphasis on programmed instruction brings into sharp focus once again the philosophical schism between Realism and Experimentalism and the attendant psychological controversy between Behaviorism and Functionalism. It is suggested in a recent analysis of the role of Thorndike's psychology, that his contributions to educational methodology, based upon a philosophical realism, served to maintain rather than significantly modify the educational practices of the early twentieth century. ${ }^{2}$ The purpose of our critique is to extend this evaluation to the Realists who are the current proponents of programmed instruction. Our thesis is that instead of being an "educational revolution" as it is heralded by some, machine learning may very well result in a further entrenchment of the contemporary methods of exerise, review, and drill. First, let us examine the underlying assumptions made by the promoters of programmed instruction to see whether they provide a basis for significant changes in educational practice.

\section{The Nature of Man}

John Dewey has highlighted the basic controversy between a mechanistic and an active problem solving orientation concerning the nature of man. ${ }^{3}$ It is this same mechanistic view, which he so vigorously criticized, which serves as a basis for programmed instruction. The central point of disagreement between the Experimentalist and the mechanistic Behaviorist resides in what Skinner has referred to as the "black box," or those processes that go on within the individual which are not directly observable. The mechanistic view declares the contents of the "black box" irrelevant to the educational mission, whereas the Experimentalist assigns these processes an important role in the individual's transactions with his environment. The view of man as an active participant in transacting with the environment leads to a different orientation toward programmed instruction than the more parsimonious conception of man as a respondent to external

DAVID C. EPPERSON is Assistant Professor of Education at the Unuersity of California at Santa Barbara.

RICHARD A. SCHMUCK is Assistant Study Director at the Institute for Social Research and teaches social psychology at the University of Michigan, Ann Arbor, Michigan.

${ }^{1}$ At the University of Michigan when the paper was written.

${ }^{2}$ Sherwood Auger, "E. L. Thorndike's Educational Psychology and the American Educational Program of the period 1890-1915." Unpublished Doctoral Dissertation, University of Michigan, 1961. 3John Dewey, "The Reflex Arc Concept in Psychology," Psychological Review III, (1896) 357-370. 
stimuli. While the proponents of automated instruction, who employ this simple input-output behavior model, recognize that not all learners will progress at the same rate, they do assume that the essential steps in the acquisition process are "logical" and the same for all men. They admit that some students will be able to take bigger steps than others, but the ordered progression will be the same for all. Man for them is a constant, being stimulated to action by energy changes in the environment.

Instructional devices which are based on mechanistic and static conceptions of man should be questioned at this point on at least two counts. First, if the learner is viewed as only mechanistically responding to the environment and as having no role in acting upon it independently, it follows that programmed instruction does little more than our current recitation and drill techniques. At best it only does them with more speed and efficiency. Thus, programmed instruction tends to be conservative, for although it promotes greater efficiency, it demands no significant modifications in basic educational procedures. This mode of instruction can be carried out within contemporary educational organizations and certainly within the framework of traditional school subjects. Involvement in "real life" transactions with dynamic environments, which is so central to the Experimentalist tradition, is not an integral part of programmed instruction. Essentially, learning is isolated from its potential points of application. ${ }^{4}$

The second question that should be raised concerns man's cognitive processes or, in other words, the contents of the "black box." Are mental phenomena really as irrelevant as the Behaviorists suggest? We believe not. Take one of their basic concepts, reinforcement, for example; and ask whether or not one can assume similar effects for all learners after making a correct response on the program. The results of one study ${ }^{5}$ indicate that introverts and extroverts respond diffierently in a learning situation to praise and blame. Introverts react more favorably to praise, while the extroverts react more favorably to blame. Another study ${ }^{6}$ indicates that the specific type of feedback given in a learning situation affects individuals with high need for achievement differently than those with high need for affiliation. Learners with high achievement motive work better under conditions of task relevant feedback, while those with high affiliation motive are more responsive to feedback of a more personal nature. Studies like these point to the importance of intervening psychological processes in the human learning process. The cognitive styles of an individual appear to predispose him to respond differently to environmental changes. This at least suggests that any one sequence of "logical steps" with its attendant illustrative material may fail to accomodate adequately for the wide range of differences in cognitive styles among learners. Educational technology in the form of programmed instruction

\footnotetext{
${ }^{4}$ Proponents of programmed instruction argue that greater efficiency is afforded by the program since more time is available for application activities. Preparation and application activities are viewed, here, as distinct segments of the learning process. Experimentalists, on the other hand, argue that learning to solve problems occurs best when preparation and application activities are articulated systematically.

${ }^{5} \mathrm{G}$. G. Thompson and C. W. Hunnicutt, "The Effect of Repeated Praise or Blame on the Work Achievement of 'Introverts' and 'Extroverts'." Journal of Educational Psychology, 1944, 35, $257-266$.

${ }^{6}$ Elizabeth G. French, "Effects of the Interaction of Motivation and Feedback on Task Performance" in Motives in Fantasy, Action and Society, J. W. Atkinson (ed.), New York, Van Nostrand, 1958, pp. 400 408 .
} 
may represent a conserving influence for contemporary education, in that it does not lend itself readily to the flexibility necessary to accomodate for 1) changes continually occurring in man's transactions with the environment and 2) differences existing among individuals. Man's dynamic nature and his infinite variability are basic themes in Experimentalist proposals for educational reform.

\section{The Nature of Knowledge}

A critical look at the assumptions concerning the nature of knowledge made by the proponents of programmed instruction raises some additional issues. These issues arise when one attempts to answer the question of what should be "fed" into the teaching machine. Programmers making such decisions are, in essence, authorities who make ultimate decisions concerning the nature of reality and truth. This epistemology clashes with the Experimentalist position which declares knowledge to be a dynamic reality, continuously being modified as learners transact with ever-changing environments. For the programmer there can be no creative participation of teacher and learner in the process of knowing; except, of course, for those few fortunate learners acting as subjects for the development of a program. It is the teacher, or some other authority, who knows the truth and whose job it is to "stamp in" this knowledge.

This procedure for establishing truth has certain socio-pclitical implications. The belief in an elite which makes decisions about the nature of reality, implicit in the programmed learning approach, precludes the opportunity for learners to challenge the status quo. For Realists the creative participation of learner with teacher in the process of knowing does not appear to be a goal in and of itself, and thus does not play an integral part in education for a democracy as envisioned by the Experimentalists. The democratic bias of the Experimentalists leads them to conceive of pupil participation in the learning process not only as a goal in itself, but as training both in learning how to learn and in learning how to participate fully in a democracy. The Experimentalist must conclude that the nature of programmed instruction can support simultaneously a belief in the right of educational authorities to establish "truth," and the status quo in educational methodology. This technology, therefore, can be conceived as a further extension of our tradition of teacher-centered instruction which might serve to impede the adoption of educational reforms designed to teach more effective participation in a democracy.

Still another highly related issue brought to mind by present trends toward the adoption of programmed instruction concerns the source of educational goals. One assumption implicit in the Realist doctrine is that basic truths exist "out there"as a part of a static reality. "The argument follows that as these truths are discovered they should serve as the basis for educational goals. This view contrasts markedly with the transitory nature of educational goals as conceived by the Experimentalist. Within an educational setting emphasizing programmed instruction, active participation by the student in setting learning goals is limited, if not precluded, by the prearranged sequence of subject matter on the program.

So far we have attempted to demonstrate that the methodological improvement promised by programmed instruction may, very well, result in a further entrenchment of present practices involving exercise, review, and rote. This conclusion is supported by the philosophical assumptions upon which programmed 
instruction is based. We will now examine some psychological assumptions made by the proponents of programmed instruction concerning the nature of the learning process.

\section{The Natute of Learning}

In the Behaviorist's efforts to deal only with theoretical constructs which lend themselves to precise operational definitions, he frequently commits errors of oversimplification. The limitations of these oversimplifications become apparent when one examines the motivational considerations upon which programmed instruction is based. It is assumed that the learner will respond because of some "unknown" motive the first time he encounters the machine. Then, once he is rewarded for responding correctly the reinforcing qualities of making this correct response serve to enhance the probability of his continuing with the learning task. In traditional learning situations, such as those of rote-drill and recitation, little attention is given to the effect of context on the motivation of the learner. At least two characteristics of the context deserve some consideration along these lines. The first of these concerns the meaningfulness that the total social context supplies for the learner, while the second involves the motivational impetus or distraction which is provided by social stimuli in the learning environment. For any particular stimulus object to have meaning for the student it must fit into some configuration of stimuli which are functional for him in coping with and understanding the world around him. The detached activity of machine manipulation does not appear to be optimal for making learning experiences meaningful and functional, or practical for the learner. Undoubtedly, for those children without superior ability in dealing with abstract concepts, correct responses made on the machine may not generalize to new problem solving situations which fail to provide the contextual clues provided by the machine learning situation. The machine does not begin to present the flexibility for transfer of training that an active problem solving approach might foster. Both the issues of the meaningfulness of materials and transfer of training, which have traditionally received considerable attention in the psychology of learning literature, are issues which when applied to programmed instruction suggest its limitations as a modality for socialization into modern life.

Interpersonal factors compose another aspect of the learning context not emphasized by the proponents of programmed instruction. It is commonplace that a child not only forms a particular style of interacting with his teachers in learning situations, but also that his experiences are being modified constantly by significant peers, either present in the immediate environment or in his phenomenal field. These important interpersonal influences condition both a student's initial interest in a learning task and his extended involvement in the completion of the task. For example, if a classroom peer group maintains a standard that defines anyone who succumbs to teacher influence as a "square," no form of systematic drill or logically ordered stimuli will significantly aid in the promotion of educational goals, even if presented under optimal conditions of reinforcement. In order for conditions of successful drill to exist, group standards which permit pupil involvement in academic learning tasks must prevail. Teacher threats certainly can be employed with drill and recitation, as they frequently are, but few educators care to base motivation to learn on fear rather than commitment. Programmed instruction leaves some central problems of motivation unsolved. 
Teachers still must find ways to get their students enthusiastically involved in learning tasks. It is in this area of involving pupils where Experimentalist teaching differs so significantly from styles of teaching which embrace programmed instruction as a primary learning modality.

For too long psychologists have failed to attend systematically to the situational context as a factor influencing learning. The area called psychological ecology is still in its infancy and has few findings which can be applied easily to classroom settings. Nevertheless, we do know that context plays a major role in perceptual phenomena, that anxiety is specific to certain contexts, and that attitudes, which often are considered to be enduring psychological phenomena, are specific to situational requirements in filling a role. These findings suggest that in all kinds of pedagogical planning we must consider the situational contexts.

In relation to the learning process, programmed instruction has numerous other limitations which should be kept in mind while evaluating it as a candidate for improving the educational process. One of the most important goals of educational institutions is to equip students with skills for mastering new and different learning tasks. Pupils should learn how to learn new things. It is doubtful that an important skill which demands so much flexibility can be successfully programmed. The everyday learning tasks of executives, doctors, laborers, etc., do not lend themselves to programmed instruction. Medical practitioners could hardly afford to stand by while an educator goes through the tedium of trial and error programming of an innovation in diagnosis or treatment. The physician, like other skilled craftsmen and men in all walks of life, needs to possess skills of knowing how to learn, and it is questionable that this can be accomplished effectively through a program.

At this time, programmed instruction cannot claim under its province any of the following: 1) learning how to seek and use varied resources in solving problems, 2) learning how to apply concepts learned in the abstract, 3) learning how to put parts together in forming a creative product. Only the most elaborate machine could be expected to provide complex evaluative feedback for this purpose, and 4) learning how to relate to other people while accomplishing a task. It becomes apparent that anyone committed to the Experimentalist position, and hence to democratic values, will emphasize these four areas which by their very nature do not lend themselves to programming. In order to teach children how to question beliefs based on authority effectively, opportunities must be offered which allow them to challenge sources of information. These democratic skills can hardly be promoted until programs are built to receive as well as to give feedback. With the current unbalanced power relation between the program and the child, the learner is not a creative participant in the process of evaluating and modifying the "truths" presented by educational authorities.

\section{Societal Pressures to Adopt Programmed Instruction}

The rapid ascendancy of programmed instruction is due, in a large measure, to other factors besides the ingenious research and development by B. F. Skinner and his colleagues. Social factors fostered primarily by a rapidly changing national and international situation serve as conditioners for the advancement of a more "efficient technology" in teaching. Increased competition for international prestige in science and technology has been accompanied by an active reappraisal 
of our utilization of human resources. Pressures like these, along with a population bulge which has increased the pupil-teacher ratio in many schools, have provided the impetus to a more active search for efficient techniques of instruction. The urgency created by national and international pressures could lead to the adoption of expedient learning devices which have not undergone close scrutiny.

Unlike social inventions, such as a new grouping procedure or team teaching, programmed instruction has an "economic advantage" for those in the economy who are in a position to benefit from its adoption. This serves as a dangerous impetus that should be weighed cautiously. Educators can expect to experience the "hard sell" as well as to be subject to more subtle pressures that can be brought to bear on them by the representatives of the entrepreneurial community, the school board.

Neither is the academic world impervious to economic advantage. Grants are being made available currently by both private enterprises and governmental agencies permitting scholars to engage actively in building programs for automated teaching. People in the academic community should take care not to make personal investments in program building that will blind them to the limitations of the modality.

Perhaps the most dangerous issue in this entire trend is the control which a small group of entrepreneurs, psychologists, and programmers could have over educational context and style of learning. Skinner, by no means, is unaware of this perplexing issue. The extended debate between Burris and Frazier in Walden $T w o^{7}$ seemingly reflects Skinner's personal dilemma concerning extensive control and planning. If teaching programs were flexible units lending themselves easily to collaborative modification by teachers and actively inquiring students, this issue of ultimate control would not be so significant. The fact of the matter is, however, that program development and evaluation is very expensive, making this kind of flexibility economically unfeasible.

In this period of advanced technology with emphasis on efficient production, the Experimentalist will not be able to turn his back on this programmed instruction movement. The real question that the movement raises is: Is it possible to participate in a reconstruction of educational procedures by adapting to these currents of change without being seduced by the apparent advantages for teaching efficiency offered by programmed instruction?

\section{Overcoming Some of the Objections to Programmed Instruction}

It appears unrealistic to conceive of significantly modifying the social forces at work leading educators to a general acceptance of programmed learning. We deem it important, therefore, to comment constructively on the ways in which programmed instruction might be used creatively as part of an Experimentalist educational reform. One might ask first: How can programmed instruction serve the goals of educational reconstruction? There seem to be ways in which programmed learning could be integrated into classrooms with a problem solving focus. First, if the curriculum were developed so that boundaries of subject matter, as we currently know them, were blurred and a problem solving, "real life" orientation pre-

'B. F. Skinner, Walden Two, New York: Macmillan, 1948. 
vailed, it would be possible to use programs and machines just as teachers, peers, books, supplies, movies, and television would be used, as other resources with unique contributions to the learning process. Programmed materials could be used when more detailed information concerning a particular class of phenomena is required for more mature problem solving. Or secondly, the student could compare a program with other sources of knowledge on the same topic and critically evaluate the usefulness of these various sources of knowledge for solving the problems he faces. Here the program represents an object of criticism. Thirdly, in the process of building programmed curricula, decisions concerning the content of a program might provide the stimulus for a re-assessment of traditional subject areas in the school curriculum. This re-evaluation could lead to attempts to help the student creatively integrate across traditional subject matter areas through the presentation of general problems on programs. This means that a more careful selection of concepts to be programmed would add to an educational process focused on establishing conditions for individual inquiry, problem solving and creativity. For instance, there might be an attempt to delete obsolete fragments of information which do not lead to an effective solution to contemporary problems.

We also want to ask: How can programmed instruction overcome criticisms aimed at a philosophical Realism? A variety of modifications could be made in program construction and classroom practice in alleviating some of these objections. First, shorter programs could serve as bridges in getting the student over certain "blind spots" in the educational process. They would never be used as the primary mode of instruction in the solution of any one class of problems such as problems of economic exchange or international understanding. Secondly, more consideration must be given by programmers to the variety of cognitive styles which are present in individual pupils. For instance, it seems quite appropriate from findings in social psychological research to use different life examples for pupils from different social backgrounds. Presumably it is the case also that children with various intellectual resources differ in their cognitive orientations to the task of learning. Conceptually adept students are able to handle more abstract levels of knowledge, while other students operate more effectively when presented with concrete illustrative materials. Along these lines it is quite appropriate, for instance, for less conceptually adept students to learn from a programmed system which utilizes two, three, or even four sense modalities. Psychological research concerning learning to read has led to similar conclusions. ${ }^{8}$ Thirdly, programs should be constructed so that they are subject to continual collaborative modification by teachers and pupils.

Negative criticisms leveled at the derivitives of a philosophical Realism can be somewhat diminished if instructional techniques incorporate procedures for dealing directly with pupil expectations also. Modifications in the procedures of classroom management should be made so that pupils are alerted and rewarded for being critical of the content, sequence, and illustrative materials represented in the program. This critical, evaluative process can be realized in two ways: First, opportunities should be set up so that pupils can give feedback to the program as they are engaged in machine learning. Secondly, pupils should be taught to question and debate the conclusions drawn by the programmer with their peers and teach-

${ }^{8}$ Grace Fernald. Remedial Techniques in Basic School Subjects. McGraw-Hill, 1943. 
ers. Procedures like these must be institutionalized and supported by teachers or we run the risk of developing passive, dependent accepters of realities as they exist for the programmers. Stamping in the "truth" should be avoided if we are to create a society in which critical inquiry and creative discussion are prominent.

Still another question arising from our analysis is: How can programmed instruction overcome the criticisms aimed at its apparent neglect of the learning context? For programmed learning to hold significance for the learner, certain contextual conditions should prevail in the classroom. First, group standards in support of individual differences must be developed and clarified. A clarification of the group standards centering around the individual's relations to the program and his relationships with other pupils is an essential objective for the teacher. Individual differences should be accepted and encouraged by the peer group. Different styles and paces of learning would best be seen as natural outgrowths of the variety of human resources that exist in the peer group. This variety should be valued by students, with each being thought of as making his own unique contribution to classroom life. In addition, immediate application situations should be provided for pupils so that materials received from the program gain a meaning outside of their program context. This should facilitate retention and render new concepts more useful.

Finally we ask: How can educators resist the pressures from the entrepreneurial world to adopt programmed products? New programs should be studied thoroughly, giving special attention to their rigidity or flexibility for modification, their applicability to a problem solving centered classroom, and their appropriateness for the variety of individual cognitive styles that exist in most instructional groups. We must not run the risk of adopting another educational tool which discriminates against the lower class child who operates from a different cognitive frame of reference than the middle class child. ${ }^{8}$ We should endeavor to make all educational decision makers; teachers, administrators, and others, as sensitive as possible to the limitations of machine teaching and of educational technology in general. And finally, we should constantly pursue alternative modes for improving educational efficiency and effectiveness. We cannot afford the luxury of complacency with any one technique of instruction in a world so in need of individuals who possess the flexibility to deal effectively with the complexities of modern living.

\section{SUMMARY}

Our purposes in this article are to call to the attention of educational reformers the basic philosophical and psychological assumptions upon which programmed instruction is based, to suggest some consequences of the adoption of such an instructional technique, and specifically to indicate that the programming movement is potentially conservative and hence inconsistent with the Experimentalist tradition. We conclude with some suggestions as to how developments in programmed instruction might be used constructively in servicing the goals of educational reconstruction in a democracy. 1960.

9D. R. Miller and G. E. Swanson. Inner Confict and Defense, New York: Henry Holt and Co., 